\title{
Formas plurais de governança no sistema agroindustrial citrícola paulista
}

\author{
Fabiana Ortiz T. Mello ${ }^{1}$ \\ Luiz Fernando Oriani Paulillo ${ }^{2}$
}

Resumo: O Sistema Agroindustrial Citrícola constitui um exemplo muito interessante de interação entre formas de governança. O mesmo produtor coordena suas transações de venda de laranja para os agentes dos canais de comercialização de várias formas, situação que na teoria é chamada de formas plurais ou mix contratual. Nas vendas para os compradores que destinam a fruta para o consumo in natura, ele realiza transações baseadas no mercado spot. Já nas negociações com a indústria de suco, predominam os contratos. O produtor pode, ainda, arrendar parte da capacidade ociosa de uma indústria para processar sua fruta e vender diretamente ao mercado (quase integração) ou integrar a venda da fruta in natura, através de barracões (hierarquia). O objetivo principal deste trabalho é identificar os fatores que explicam a decisão do citricultor em vender para diferentes compradores empregando governanças distintas. Uma das conclusões acerca dos determinantes das formas plurais no caso citrícola está relacionada ao fato de existir necessidades específicas por parte dos compradores que pertencem a canais de distribuição distintos, gerando restrições que tornam a decisão por múltiplos canais e formas de governança a única opção para muitos produtores. Porém, a principal conclusão é a de que as transações entre produtores e os canais de distribuição diferem em pelo menos um dos atributos (especificidade de ativos, frequência ou incerteza), o que explica a adoção de formas diferentes de coordenação.

Palavras-chaves: sistema agroindustrial citrícola, governança, formas plurais, custos de transação.

\footnotetext{
${ }^{1}$ Economia pela Universidade de São Paulo(FEA-USP); Mestre e Doutora em Engenharia de Produção pela Universidade Federal de São Carlos (UFSCar). Professora da Fundação Educacional de Penápolis (Funepe) e da Faculdade de Tecnologia de Lins (Fatec). E-mail: fabianaortiz@uol.com.br

2 Professor Associado do Departamento de Engenharia de Produção da Universidade Federal de São Carlos (UFSCar), pesquisador do Grupo de Ensino e Pesquisas Agroindustriais (GEPAI) da UFSCar e Pesquisador do CNPQ-Bolsa Produtividade em Pesquisa. Doutor em Economia pela Unicamp. E-mail: dlfp@power.ufscar.br
} 


\begin{abstract}
The citrus agroindustrial system is a very interesting example of the interaction of different forms of governance. The same producer manages his orange sales to the market agents in different ways: this situation is called plural forms or contractual mix. On sales to purchasers that sell the fruit for in natura consumption, the producer deals in terms of spot market. On the other hand, contracts are predominant in transactions with juice-processing industry. The producer can also lease part of the unused capacity of an industry in order to process his own fruit and sell it straight to the market (quasi-integration) or integrate the sale of the in natura fruit becoming the owner of sheds (hierarchy). This work aims at identifying reasons that lead citrus growers to sell their product to different purchasers employing different governances. One of the conclusions on the determinants of plural forms in the case of citrus growing is linked to the fact that buyers from distinct channels of distribution (quantity, quality, fruit variety, location) have specific needs, which create restrictions that make the choice for multiple channels and forms of governance the only one available for many producers. Nevertheless, the main conclusion is that the attributes of the transaction are the key factors to explain the occurrence of plural forms, i.e., it is the fact that transactions between producers and members of distribution channels are different in at least one attribute (specificity of assets, frequency or uncertainty) that explains the adoption of different forms of coordination. As a result, citrus producers do not show inabilities to measure such attributes and, in especial, to identify the most efficient solution in terms of governance, making contractual mix a stable situation rather than a transitory one.
\end{abstract}

Key-words: citrus agroindustrial system, plural forms, governance, transaction cost.

Classificação JEL: D23.

\title{
1. Introdução
}

O emprego simultâneo de diferentes estruturas de governança para coordenar as transações de uma mesma firma - situação conhecida como formas plurais ou mix contratual na literatura - intriga a economia das organizações e, particularmente, a lógica da Economia dos Custos de Transação (ECT). Para essa perspectiva teórica, espera-se que a firma encontre uma única estrutura de governança alinhada às características de uma transação e ao ambiente institucional vigente.

Contudo, a melhor estratégia pode não ser simplesmente a escolha da forma mais eficiente, ou seja, aquela que minimiza custos de transação segundo a teoria de Williamson (1985), mas o estabelecimento de diversas formas (plurais).

Várias são as razões que levam à ocorrência de formas plurais de coordenação. Alguns defendem que essa estratégia permite minimizar a soma dos custos de produção e dos custos de transação. Para outros, a operação simultânea em vários canais e o emprego de diferentes estruturas de governança permitem à firma combinar estratégias para aproveitar o melhor de cada estrutura e, também, beneficiam-na da complementaridade existente entre elas. 
As características ou objetivos da contraparte da transação - o comprador também podem fornecer explicações importantes para a ocorrência de formas plurais. Quando esse agente, por exemplo, quer obter maior flexibilidade para enfrentar incerteza quanto ao suprimento (quantidade) e à qualidade da fruta, forçando a adoção de governanças distintas nas negociações com seus fornecedores.

Particularmente nos sistemas agroindustriais, a comercialização de produtos perecíveis coloca desafios como atender as preferências diversas do consumidor final com uma produção que é incerta em quantidade e qualidade, submetendo as transações à extrema incerteza e a coordenação à crescente complexidade. Esses aspectos, segundo Brousseau e Codron (1997), trazem assuntos interessantes de governança para esse segmento. No sistema agroindustrial citrícola, é possível verificar situações em que o mesmo produtor emprega, simultaneamente, formas distintas de governança nas transações com os diversos agentes dos canais de distribuição (indústria processadora, barracões, varejistas, intermediários e mercado institucional). As formas empregadas vão desde o mercado spot, passando pelos contratos de curto, médio e longo prazos e pela quase integração, através do tool processing (formas híbridas), indo até a integração vertical, na qual alguns produtores são proprietários de barracões.

Nesse contexto, o objetivo principal deste trabalho é identificar os fatores que explicam a decisão do produtor em vender para diferentes compradores empregando governanças distintas, ou seja, explicar os motivos para a existência de formas plurais.

Seguindo essa introdução, o próximo tópico faz uma explanação dos métodos e técnicas utilizados na pesquisa, bem como da forma de análise das informações colhidas na pesquisa de campo. O terceiro item faz uma revisão do referencial teórico que fundamenta o trabalho, apresentando os principais conceitos da ECT e as principais contribuições de autores da Economia das Organizações para explicar a coexistência de governanças distintas dentro de uma mesma firma em redes de franquias, em sistemas agroindustriais e em canais de distribuição. O quarto tópico analisa as transações entre citricultores e os compradores de laranja (indústria de suco e canais de venda da fruta in natura) na região selecionada, apresentando explicações para o mesmo produtor empregar formas distintas de governanças. $\mathrm{O}$ trabalho se encerra com as considerações finais.

\section{Metodologia}

Dentre os níveis de pesquisa abordados por Gil (1987), o explicativo é considerad o o mais indicado para este trabalho, pois tem o objetivo primordial de identificar os fatores que determinam ou que contribuem para a ocorrência dos fenômenos (a coexistência de formas plurais para coordenar as transações de venda de laranja). Para o autor, esse é o tipo de pesquisa que mais aprofunda o conhecimento da realidade, uma vez que explica o porquê das coisas. 
A pesquisa será delineada com base no tipo levantamento de dados, que consiste na interrogação direta das pessoas acerca do problema estudado e posterior análise quantitativa dessas informações para se tirar conclusões, conforme Gil (1987).

Para a execução da parte empírica, o trabalho utilizou as informações colhidas na pesquisa de campo junto a uma amostra de 120 citricultores localizados na maior região produtora de laranja do País, a região de Barretos (Barretos, Bebedouro, Monte Azul, Taquaral, Taiaçu e Pirangi), onde foram encontrados todos os aspectos do cinturão citrícola, quais sejam: pomares novos e velhos, várias processadoras e associações de citricultores, prestadores de serviços e produtores que vendem para todos os canais de distribuição.

A aplicação de dois questionários estruturados a estes produtores teve como objetivo captar vários dados, que foram comparados para dois grupos de produtores: 1) aqueles que empregam uma forma "singular" de governança para coordenar as transações de venda de laranja para vários compradores e 2) aqueles que adotam formais "plurais".

Para atender aos objetivos do trabalho, serão apresentados os dados de estatística descritiva dos produtores (média, frequência, máximo, mínimo e desvio padrão) e os testes de hipóteses, procedimento que já dá uma forte indicação das variáveis que explicam a adoção do mix contratual. Contudo, para comprovar a significância dessas variáveis e seu efeito sobre a probabilidade de adoção de formas plurais, foram elaboradas regressões utilizando dois modelos para avaliar a consistência das estimações: o Modelo Logit e o Probit. A variável dependente "adoção de formas plurais" é uma Dummy que foi modelada como uma ocorrência binária, que assume o valor 1 para os produtores que empregam formas plurais e 0 para os que empregam uma única forma de governança.

De acordo com Wooldridge (2006), esses modelos são os mais indicados para os casos em que a variável dependente é do tipo qualitativa, sendo a função de regressão interpretada como uma probabilidade prevista, ou seja, explica-se o efeito de alterações nas variáveis explicativas sobre a probabilidade de resposta da variável dependente.

Em relação às variáveis explicativas, foram consideradas:

- Quantidade de laranja comercializada (variável submetida a transformação logarítmica);

- Participação do produtor em organização social (sindicato, organização setorial e pool de comercialização). Variável binária indicando (1) para participação e (0) para não participação;

- Nível de escolaridade do produtor (em anos de estudo);

- Preço médio recebido por caixa de laranja (submetida a transformaçãologarítmica);

- Tempo de transporte da propriedade até o ponto de entrega da laranja (em minutos); 
- Frequência das transações;

- Diferença entre o preço esperado e o efetivamente recebido pelo produtor (incerteza);

- Presença de ativos específicos na transação.

Na pesquisa de campo, foram coletadas informações que permitiram identificar quais são as especificidades envolvidas na produção de laranja, a frequência das transações e as percepções dos produtores quanto à incerteza e outros possíveis entraves à efetivação das transações, bem como a descrição das formas de governança empregadas. De posse dessas informações, foi possível verificar se a estrutura de governança escolhida está alinhada às características das transações, conforme propõe a Economia dos Custos de Transação (ECT), e testar o primeiro argumento teórico que explica a adoção de formas plurais (diferentes atributos das transações).

\section{A Economia dos Custos de Transação}

O conceito de transação é definido por Williamson (1993) como a transformação de um bem ao longo de interfaces tecnologicamente separáveis. Como as transações podem assumir uma variedade de formas, faz-se necessário um arcabouço completamente sistematizado para que os propósitos dessas negociações sejam cumpridos. É nesse contexto que cresce a importância das governanças que permitem coordenar as transações econômicas, mostrando os limites dos modos de análises tradicionais e impulsionando os estudos da Economia dos Custos de Transação(ECT).

O arcabouço teórico da ECT torna a análise organizacional mais complexa, pois considera que os agentes econômicos se interagem visando reduzir não somente os custos ligados à produção, como pregava a economia ortodoxa, mas também aqueles ligados às transações. Esse novo corpo de conhecimento suplanta a preocupação até então dedicada à tecnologia e ao estado da produção, introduzindo custos comparativos de planejar, adaptar e monitorar tarefas sob diferentes formas organizacionais.

Williamson (1991) distingue três formas básicas de governança das transações: a) mercado ou spot; b) formas híbridas ou contratuais e c) hierarquia ou integração vertical. Para o autor, há razões econômicas racionais para organizar algumas transações de uma maneira e outras transações de outra maneira, sendo que a governança adequada tem que ser capaz de resolver o conflito entre as partes e de impedir ou atenuar conflitos potenciais. Nesse contexto, o autor considera que estruturas eficientes de governança, ou seja, aquelas economizadoras de custos de transação são resultados do alinhamento destas aos atributos das transações, sob condições de racionalidade limitada dos agentes e oportunismo. Os atributos fundamentais das transações são: a) especificidade dos ativos envolvidos, b) incerteza à qual as transações estão submetidas e, c) frequência com que se realizam as transações. 
Segundo Williamson (1985, p.65), a especificidade dos ativos, que representa o mais importante indutor da forma de governança, corresponde a investimentos duráveis que se realizam em apoio a transações particulares, cujo custo de oportunidade é muito menor nos melhores usos alternativos se a transação original termina prematuramente. Portanto, são ativos de propósitos especiais, e não gerais, que não podem ser utilizados de forma alternativa sem uma perda considerável de valor.

Williamson (1991, p. 275) distingue seis tipos de especificidade de ativos: a) Especificidade locacional: refere-se à redução nos custos de transporte e armazenagem através da localização estratégica entre firmas de uma mesma cadeia produtiva; b) Especificidade de ativos físicos: quando são requeridos instrumentos ou equipamentos especializados para a produção de um bem para o cliente; c) Especificidade de ativos humanos: está relacionada às habilidades ou ao aprendizado específico de uma determinada atividade; d) Especificidade de ativos dedicados: quando a expansão da capacidade produtiva é adotada por uma das partes com o propósito único de responder ao incremento da quantidade demandada pela outra parte, convertendo-se em ativo específico; e) Especificidade temporal: na qual o valor de uma transação depende do tempo em que ela se processa. Inclui produtos nos quais o tempo é um fator fundamental para a atribuição de valor ou para a eficiência no processo produtivo.

A incerteza ou risco, um segundo atributo das transações, tem importância central na ECT, em razão do pressuposto da racionalidade limitada dos agentes, segundo o qual os atores são incapazes de desenhar um contrato que contemple todas as contingências futuras.

A incerteza representa perturbações exógenas que afetam o processo de troca, sendo que as partes têm que se adaptar a elas. Para Hayek (1945) apud Williamson (1985, p. 66), a incerteza pode ser de dois tipos: a primária, que depende do estado e deriva de atitudes aleatórias e mudanças imprevisíveis, e a secundária, que deriva do fato daquele que toma decisões não poder conhecer os planos e intenções da outra parte (falta de comunicação).

No caso de transações que envolvem ativos específicos, o aumento da incerteza é mais importante. Isso porque as partes têm que elaborar um sistema para resolver os pontos da transação, pois as brechas contratuais serão, possivelmente, maiores.

A frequência com que a relação entre as partes é estabelecida é outra dimensão da transação. Este atributo é importante porque quanto mais transações houver, maior a possibilidade de diluir os custos de adoção de um mecanismo de governança complexo.

Williamson (1991) argumenta que, quando as transações são esporádicas, com baixo nível de especificidade dos ativos, e quando os preços são suficientes para motivar os agentes, a forma pura de mercado pode representar a maneira mais eficiente de coordenação, já que a hierarquia incorre em custos burocráticos desnecessários. Por outro lado, quando as transações são recorrentes, na 
presença de especificidade de ativos e de incerteza, a forma contratual é a mais indicada, pois reduz os riscos de oportunismo.

Portanto, a contribuição de Williamson permitiu avançar na questão da eficiência organizacional, já que estruturas mal-escolhidas ou mal-adaptadas à transação levam a dificuldades de coordenação.

\section{Abordagens sobre formas plurais de governança}

A literatura de formas plurais apresenta uma variedade de argumentos para explicar o fenômeno, porém, sem nenhuma conclusão sedimentada. Esses argumentos podem ser classificados em três grupos, que serão analisados a seguir: (a) Diferentes atributos das transações; (b) Formas plurais como uma situação transitória e (c) Formas plurais estáveis.

\subsection{Diferentes atributos das transações}

Segundo alguns autores, a explicação para o emprego das formas plurais está alinhada ao modelo de Williamson (1991), que aponta que diferentes mecanismos realmente governam transações diferentes em pelo menos um atributo. Para Minkler e Park (1994), os diferentes níveis de especificidade de ativos envolvidos nas transações estabelecidas pela firma é o que justifica a presença simultânea de distintos mecanismos de governança. No caso das franquias, como o ativo mais específico envolvido na transação é a marca, uma firma pode decidir por uma proporção de lojas integradas para evitar o comportamento oportunista e o não cumprimento dos procedimentos que sustentam o valor da marca por parte de alguns franqueados. Fan (1995) defende o uso de estruturas integradas ou híbridas em áreas onde a especificidade de ativos e a incerteza sobre o desempenho do negócio têm maior ou menor intensidade.

Portanto, embora as transações com diferentes agentes sejam similares, cada transação tem pelo menos um atributo diferente e, por isso, é coordenada por uma governança distinta, justificando a adoção de formas plurais.

\subsection{Formas plurais como uma situação transitória}

No segundo grupo de argumentos sobre a adoção de formas plurais estão autores que defendem a ideia de que transações similares podem implicar num mix contratual transitório, com uma estrutura de governança singular devendo prevalecer no longo prazo.

Para Cave e Murphy (1976), a coexistência de governanças distintas no segmento de franquias é uma situação transitória e um instrumento de controle utilizado pela firma, sendo explicada pelas características do mercado e pela existência de ativos intangíveis. Assim, a manutenção de lojas integradas 
aumentaria na medida em que crescem as dificuldades em cobrar dos franqueados os benefícios proporcionados por ativos intangíveis e, quando o sistema ganhasse maturidade, diminuiria o custo do capital para o franqueador.

Rubin (1978) e Gallini e Lutz (1992) explicam a existência de formas plurais como resultado da busca por uma situação de equilíbrio entre incentivo e controle, constituindo-se num mecanismo de proteção da firma. Os contratos de franquias, apesar de estarem sujeitos a ações oportunistas, apresentam elevado poder de incentivo. Já a governança integrada, num ambiente de assimetria de informações, permite maior controle e redução dos custos de informação. No começo do negócio, manter uma elevada proporção de lojas integradas permite sinalizar alta qualidade para os potenciais franqueados, com o objetivo de proteger o valor da marca. Quando esse valor estiver estabelecido, essa sinalização passa a ser menos requerida. Outra explicação do autor está relacionada aos problemas de restrição de recursos, optando-se por estruturas híbridas num primeiro momento. Com o fim dessas restrições externas, a firma poderia, portanto, voltar progressivamente a integrar suas atividades.

A explicação de Bai e Tao (1996) é de que a multiplicidade de governanças é um caminho temporário para induzir esforços na busca do desenvolvimento da marca. Na mesma linha de análise, Lewin e Solomon (1999) apontam a multiplicidade de governanças como um esquema de comprometimento usado pela firma para dar incentivos à outra da parte da transação e inovar o produto e/ou o processo de produção.

No âmbito dos sistemas agroindustriais, a questão das formas plurais foi tratada por Zylbersztajn e Nogueira (2002), que pressupõem que o arranjo mais eficiente será gradativamente adotado pelos agentes, ou seja, governança alternativas podem coexistir como pontos de desequilíbrio em um processo de ajuste. Para os autores, a pluralidade de arranjos pode ser explicada por: (a) situações de desequilíbrio, nas quais a presença de formas plurais pode representar uma situação de ajuste entre formas atuais e futuras, movidas por modificações nas características das transações; (b) barreiras para a adoção de uma governança nova e superior devido à existência de rotinas específicas intransferíveis; (c) efeitos do ambiente institucional no qual a governança ocorre como fato gerador de múltiplos alinhamentos.

\subsection{Formas plurais estáveis}

Para os autores que defendem o argumento do mix contratual estável, na ausência de mudanças exógenas nas condições de escolha da estrutura de governança, ou seja, nos atributos das transações, a proporção entre uma estrutura e outra deve se manter estável. A principal justificativa para essa estabilidade é de que ela deve ocorrer para explorar alguma sinergia entre mecanismos de governança complementares. 
Lewin e Solomons (1999) defendem que uma forma a é usada por uma razão e a forma $\underline{b}$ por outra, mas a firma precisa de ambas coexistindo para o sistema funcionar bem. Empregando formas distintas simultaneamente, um tipo de governança pode encontrar uma eficiência dinâmica que seria impossível em um sistema com somente uma forma singular, concluindo que a interação de formas organizacionais produz um resultado que é maior que a soma das partes. Por isso, ao escolher uma governança, a firma deve considerar mais do que as características que afetam aquela transação individualmente, sob pena de escolher uma forma de coordenação de modo subótimo.

Argyres e Liebeskind (1999) também ressaltam que a escolha da estrutura de governança para uma dada transação é inseparável de todas as outras transações de que a firma toma parte, somada com sua estratégia organizacional e de barganha. Para os autores, a governança para qualquer transação nova em que a firma se engaje deve estar ligada inseparavelmente à governança de outras transações na qual a firma já esteja engajada. Essa condição chamada de "governance inseparability" limita a habilidade da firma para diferenciar ou mudar sua estrutura no futuro, fazendo com que escolhas passadas influenciem as opções e tipos de mecanismos que poderão ser adotados no futuro.

Ehrmann e Spranger (2004) também defendem o emprego de formas plurais com a intenção de realizar certas sinergias que não existiriam se apenas uma forma de governança fosse utilizada para coordenar transações similares. Para os autores, as firmas pluralmente organizadas obtêm efeitos positivos: (a) minimizam os custos de agência vindos da incerteza quanto ao comportamento da outra parte; (b) obtêm maior crescimento; (c) se beneficiam dos impactos sobre seu sistema de qualidade, e (d) reduzem o risco individual quando mudam as condições econômicas. Nessa mesma linha, Bradach (1997) e Bradach e Eccles (1989) enfatizam as complementaridades entre dois arranjos contratuais com o objetivo de manter qualidade e homogeneidade do negócio, captar informações e ideias externamente, promover inovações e reduzir os riscos e a vulnerabilidade.

No âmbito dos sistemas agroindustriais, Brousseau e Codron (1997) defendem que a coexistência de formas plurais promove complementaridade à firma, permitindo ao distribuidor: (a) combinar estratégia de preços e qualidade; (b) garantir flexibilidade para enfrentar incertezas sobre a quantidade e a qualidade da produção e (c) permitir que o aprendizado de uma governança seja utilizado no gerenciamento da outra, acarretando um efeito de aprendizado cruzado: o mercado requer informações que são obtidas através dos relacionamentos firmados nos contratos e, ao mesmo tempo, o mercado traz informações essenciais sobre a relação entre oferta e demanda, qualidade e categoria de produtos viáveis. Assim, a coexistência de várias formas gera resultado maior que a adoção de uma única forma, revelando que, além de serem alternativos, os mecanismos são complementares. 


\section{Resultados e Discussão}

Considerando que o objetivo do trabalho é explicar a ocorrência de formas plurais de governança nas transações entre citricultores e os canais de distribuição, o corte mais próximo do ideal para a amostra é aquele que separa os produtores que empregam um único mecanismo de governança (Forma Singular) dos que empregam mais de um mecanismo (Formas Plurais). Assim, os 120 produtores da região selecionada foram classificados nesses dois grupos.

Do total de 120 produtores pesquisados, 54 empregaram uma única estrutura para coordenar as transações com agentes dos canais de distribuição na safra 2003/04 e 29 produtores empregaram mais de uma estrutura simultaneamente. Os 37 produtores restantes não foram considerados na análise porque realizaram apenas uma transação com um comprador durante toda a safra, não contribuindo, portanto, para a explicação das formas plurais no sistema agroindustrial citrícola. A tabela 1 sintetiza estes dados.

Tabela 1. Número de produtores, número de transações e quantidade de laranja comercializada (caixas de 40,8 kg) sob diversas estruturas de governança - safra 2003/04.

Governança

\begin{tabular}{|c|c|c|c|c|}
\hline 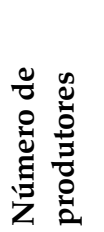 & 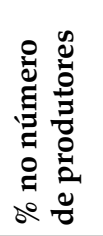 & 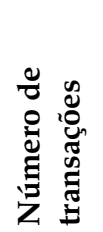 & 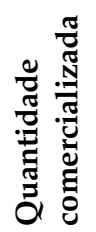 & 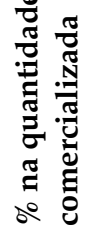 \\
\hline
\end{tabular}

FORMA SINGULAR

\begin{tabular}{lccccc} 
- Hierarquia & 1 & 1,8 & 3 & 9.000 & 0,8 \\
- Contrato & 42 & 77,7 & 122 & 1.087 .162 & 96,1 \\
- Mercado & 11 & 20,5 & 26 & 34.426 & 3,1 \\
Subtotal & $\mathbf{5 4}$ & $\mathbf{6 5}$ & $\mathbf{1 5 1}$ & $\mathbf{1 . 1 3 0 . 5 8 8}$ & $\mathbf{7 2}$ \\
\hline FORMAS PLURAIS & & & & & \\
$\quad$ - Hierarquia e Mercado & 1 & 3,5 & 4 & 124.100 & 28,0 \\
- Quase integração e Mercado & 1 & 3,5 & 4 & 9.900 & 2,2 \\
- Contrato e Mercado & 27 & 93,0 & 80 & 308.322 & 69,8 \\
Subtotal & $\mathbf{2 9}$ & $\mathbf{3 5}$ & $\mathbf{8 8}$ & $\mathbf{4 4 2 . 3 2 2}$ & $\mathbf{2 8}$ \\
\hline TOTAL & $\mathbf{8 3}$ & $\mathbf{1 0 0}$ & $\mathbf{2 3 9}$ & $\mathbf{1 . 5 7 2 . 9 1 0}$ & $\mathbf{1 0 0}$ \\
\hline
\end{tabular}

Fonte: Pesquisa de campo. 
A tabela 1 mostra a importância do mix contratual na região citrícola analisada, onde $35 \%$ dos produtores selecionados empregaram mais de um mecanismo para coordenar suas transações de venda de laranja, correspondendo a $28 \%$ da quantidade comercializada.

As formas de governança encontradas na região da pesquisa foram: mercado spot, contrato, quase integração (tool processing) e hierarquia. O mercado representa a venda sem qualquer tipo de arranjo contratual, em que as transações são feitas dia a dia na época da maturação da fruta e são motivadas pela busca do melhor preço por parte do comprador, que o define de acordo com a oferta e demanda no momento da negociação. A identidade das partes não é relevante, $\mathrm{e}$ as relações são esporádicas, não havendo compromisso de que a transação se repita no futuro. O contrato é empregado em transações que se desenvolvem em um período de tempo, em que as relações são continuadas e caracterizadas pela regularidade no volume transacionado, consistência na qualidade do produto e certa padronização dos preços. Podem ser contratos com duração de uma safra, com as negociações ocorrendo baseadas na oferta e na demanda de laranja no ano de efetivação do contrato, e os preços e a duração do contrato sendo determinados pela demanda da própria processadora naquele período. $\mathrm{Ou}$ contratos com duração de várias safras, quando o produtor comercializa um volume maior de laranja de qualidade superior com a indústria processadora, obtendo preços mais altos que os de mercado. A quase integração é quando o produtor, isoladamente ou em grupos, arrenda parte da capacidade ociosa da indústria para processar sua fruta e vender diretamente para o mercado internacional, e a hierarquia, quando o produtor é proprietário do barracão, de outros canais de distribuição da fruta in natura ou de alguma indústria processadora de suco.

Por meio do mapeamento das governanças, foi possível constatar que a ocorrência de formas plurais no caso citrícola está totalmente ligada à questão do produtor vender para compradores de canais distintos de comercialização, o que significa que o citricultor emprega governanças diferentes porque vende para compradores com necessidades diferentes. Não há casos, dentre os analisados, em que o produtor vende para compradores do mesmo canal empregando governanças distintas, o que faz com que a explicação para a ocorrência de formas plurais passe, em primeiro lugar, pela explicação do por que o produtor vende simultaneamente para compradores de diferentes canais de distribuição.

A tabela 2 apresenta os dados estatísticos (média, mínimo, máximo e desvio padrão) para as variáveis quantidade de caixas de laranja comercializada, preço médio recebido pela caixa de laranja, tempo médio de transporte da propriedade rural até o ponto de entrega da laranja, nível de escolaridade do produtor e grau de participação do citricultor em organização social para os dois grupos de produtores analisados: 
Tabela 2. Estatísticas descritivas das variáveis relacionadas às características dos produtores e das transações de venda de laranja sob diferentes estruturas de governança - safra 2003/04.

\begin{tabular}{|c|c|c|c|c|c|c|c|}
\hline Nome da variável & Governança & Freq. & Média & Mínimo & Máximo & D.P & Valor P \\
\hline \multirow{9}{*}{$\begin{array}{l}\text { Quantidade } \\
\text { de laranja } \\
\text { comercializada } \\
\text { (caixas de } 40,8 \mathrm{~kg} \text { ) }\end{array}$} & Forma Singular & 151 & 7.487 & 70 & 50.000 & 9.951 & 0,0248 \\
\hline & Hierarquia & 3 & 3.000 & 800 & 7.000 & 3.469 & \\
\hline & Contrato & 125 & 8.911 & 350 & 50.000 & 10.564 & \\
\hline & Mercado & 26 & 1.324 & 70 & 3.116 & 1.077 & \\
\hline & Formas Plurais & 83 & 4.685 & 15 & 40.000 & 8.817 & \\
\hline & Hierarquia & 2 & 2.000 & 2.000 & 2.000 & 0,0000 & \\
\hline & Quase integração & 3 & 31.333 & 14.000 & 50.000 & 18.037 & \\
\hline & Contrato & 45 & 6.106 & 200 & 40.000 & 8.664 & \\
\hline & Mercado & 38 & 1.041 & 15 & 7.000 & 1.377 & \\
\hline \multirow{9}{*}{$\begin{array}{l}\text { Preço médio } \\
\text { recebido pelo } \\
\text { produtor } \\
(\mathrm{R} \$ / \text { caixa })\end{array}$} & Forma singular & 151 & 7,09 & 2,0 & 11,4 & 1,5704 & 0,0328 \\
\hline & Hierarquia & 3 & 7,00 & 7,00 & 7,00 & 0,0000 & \\
\hline & Contrato & 122 & 6,90 & 2,4 & 11,4 & 1,3568 & \\
\hline & Mercado & 26 & 7,95 & 2,0 & 12,0 & 2,1558 & \\
\hline & Formas plurais & 88 & 6,52 & 14,22 & 1,0 & 2,1975 & \\
\hline & Hierarquia & 2 & 4,00 & 4,00 & 4,00 & 0,000 & \\
\hline & Quase integração & 3 & 8,40 & 8,40 & 8,40 & 0,000 & \\
\hline & Contrato & 45 & 6,11 & 7,5 & 4,5 & 0,8854 & \\
\hline & Mercado & 38 & 6,62 & 14,2 & 1,0 & 2,8696 & \\
\hline \multirow{9}{*}{$\begin{array}{l}\text { Tempo da } \\
\text { propriedade } \\
\text { rural até o } \\
\text { ponto de } \\
\text { entrega da } \\
\text { laranja } \\
\text { (minutos) }\end{array}$} & Forma Singular & 151 & 65,36 & 25 & 150 & 33,0913 & 0,0003 \\
\hline & Hierarquia & 3 & 120,00 & 120 & 120 & 0,0000 & \\
\hline & Contrato & 122 & 67,54 & 20 & 150 & 32,4690 & \\
\hline & Mercado & 26 & 48,84 & 20 & 110 & 28,3305 & \\
\hline & Formas Plurais & 88 & 83,80 & 20 & 150 & 40,6400 & \\
\hline & Hierarquia & 2 & 90,00 & 90 & 90 & 0,0000 & \\
\hline & Quase integração & 3 & 90,00 & 90 & 90 & 16,4316 & \\
\hline & Contrato & 45 & 89,04 & 25 & 150 & 42,3833 & \\
\hline & Mercado & 38 & 73,72 & 30 & 150 & 37,5695 & \\
\hline \multirow{9}{*}{$\begin{array}{l}\text { Nível de } \\
\text { escolaridade } \\
\text { do produtor } \\
\text { (anos de estudo) }\end{array}$} & Forma Singular & 151 & 9,37 & 3 & 16 & 6,0405 & 0,0058 \\
\hline & Hierarquia & 3 & 16,00 & 0 & 16 & 0,0000 & \\
\hline & Contrato & 122 & 10,00 & 2 & 16 & 6,1416 & \\
\hline & Mercado & 26 & 5,65 & 3 & 16 & 3,8465 & \\
\hline & Formas Plurais & 88 & 7,42 & 3 & 16 & 4,6774 & \\
\hline & Hierarquia & 2 & 4,00 & 4 & 4 & 0,0000 & \\
\hline & Quase integração & 3 & 3,00 & 3 & 3 & 0,0000 & \\
\hline & Contrato & 45 & 7,97 & 3 & 16 & 4,7313 & \\
\hline & Mercado & 38 & 7,40 & 3 & 16 & 4,7226 & \\
\hline \multirow{10}{*}{$\begin{array}{l}\text { Grau de participação } \\
\text { do produtor em } \\
\text { organização } \\
\text { social }\end{array}$} & Governança & $\begin{array}{l}\text { Freq. } \\
\text { (SIM) }\end{array}$ & $\%$ & $\begin{array}{l}\text { Freq. } \\
\text { (NÃO) }\end{array}$ & $\%$ & $\begin{array}{l}\text { Freq. } \\
\text { TOTAL }\end{array}$ & \\
\hline & Forma Singular & 97 & 64,24 & 54 & 35,76 & 151 & 0,0495 \\
\hline & Hierarquia & 0 & 0,00 & 3 & 100,00 & 3 & \\
\hline & Contrato & 91 & 74,59 & 31 & 25,41 & 122 & \\
\hline & Mercado & 6 & 35,29 & 11 & 64,70 & 17 & \\
\hline & Formas Plurais & 76 & 86,36 & 12 & 13,64 & 88 & \\
\hline & Hierarquia & 2 & 100,00 & 0 & 0,00 & 2 & \\
\hline & Quase integração & 3 & 100,00 & 0 & 0,00 & 3 & \\
\hline & Contrato & 39 & 86,67 & 6 & 13,33 & 45 & \\
\hline & Mercado & 32 & 84,21 & 6 & 15,79 & 38 & \\
\hline
\end{tabular}

Fonte: Pesquisa de campo. 
Os valores dos coeficientes e dos testes relativos à significância das variáveis constam na tabela a seguir:

Tabela 3. Estimação dos determinantes das formas plurais.

\begin{tabular}{|c|c|c|c|c|}
\hline \multirow{2}{*}{ Nome da variável } & \multicolumn{2}{|c|}{ LOGIT } & \multicolumn{2}{|c|}{ PROBIT } \\
\hline & Coeficiente & Signif. & Coeficiente & Signif. \\
\hline Intercepto & 3,646510 & 0,018 & 2,088082 & 0,014 \\
\hline $\begin{array}{l}\text { Participação do produtor em } \\
\text { organização social (Dummy) }\end{array}$ & 1,130669 & 0,004 & 0,685915 & 0,003 \\
\hline Nível de escolaridade do produtor & $-0,053836$ & 0,055 & $-0,031800$ & 0,056 \\
\hline $\begin{array}{l}\text { Quantidade de laranja } \\
\text { comercializada (log) }\end{array}$ & $-0,463618$ & 0,000 & $-0,271832$ & 0,000 \\
\hline $\begin{array}{l}\text { Preço médio recebido pelo } \\
\text { produtor (log) - } \mathrm{R} \$ / \text { caixa }\end{array}$ & $-1,103629$ & 0,061 & $-0,637659$ & 0,058 \\
\hline $\begin{array}{l}\text { Tempo de transporte da propriedade ao } \\
\text { ponto de entrega da laranja - minutos }\end{array}$ & 0,014241 & 0,001 & 0,008519 & 0,001 \\
\hline
\end{tabular}

Fonte: Pesquisa de campo.

A tabela 3 mostra consistência entre os dois modelos utilizados, nos quais a significância das variáveis e os sinais dos coeficientes são similares.

\subsection{Quantidade de laranja comercializada}

A primeira e mais importante variável para explicar a pluralidade é a quantidade de laranja comercializada pelo produtor. Os dados da tabela 2 e o efeito negativo dessa variável nos modelos estimados mostram que a adoção de formas plurais ocorre em maior proporção entre os produtores menores e a forma singular entre os produtores de maior porte.

Do lado da demanda, particularmente no caso da indústria de suco, a necessidade de manter regularidade no suprimento para garantir a ocupação da sua capacidade produtiva, de se beneficiar das economias de escala e de garantir consistência na qualidade da fruta processada (para reduzir custos de mensuração e coibir comportamentos oportunistas), faz com que esse comprador prefira adquirir laranja de produtores maiores mediante arranjo contratual. Portanto, interessa às processadoras ter o grande produtor como dedicado, vendendo toda a sua produção exclusivamente para ela, o que justifica a ocorrência de poucos produtores grandes empregando formas plurais.

Mas o que explicaria o fato de a indústria também comprar a fruta de pequenos e médios produtores se o grande é mais interessante para atender às suas necessidades? A resposta para essa indagação passa pela questão da barganha. A indústria não abre mão dos produtores menores porque, com isso, deixaria de explorar a vantagem que ela tem sobre os pequenos em termos de poder de negociação, viabilizando transações com preços menores (como mostra a tabela 2) e 
com condições de pagamento mais vantajosas. Além disso, o suprimento dos grandes produtores, juntamente da laranja colhida dos pomares próprios, pode não completar o mix e a quantidade de fruta necessária para processamento, somado ao fato de a indústria ficar concentrada nas mãos de grandes produtores, aumentando os riscos que são inerentes a qualquer transação na qual a dedicação é elevada.

No caso dos canais alternativos, particularmente dos barracões, também há uma preferência por fornecedores maiores, pelos mesmos motivos apontados para a indústria (regularidade no suprimento, economias de escala, garantia de consistência na qualidade da fruta etc.), o que justifica a maior ocorrência de pluralidade entre os produtores de menor porte. Para os pequenos, fica muitas vezes a opção de vender para vários compradores com menor necessidade de escala, como os varejistas e os agentes do mercado institucional.

Ao analisar o lado da oferta, é possível concluir que, diante das restrições de escala colocadas pela indústria, que dá preferência para os produtores maiores, o citricultor aproveita para escoar pelo menos parte da sua produção para esse canal, tendo garantia de venda, confiança no relacionamento e no recebimento, que são assegurados pelo controle que o próprio contrato exerce. Por outro lado, recebe preços menores em função do baixo poder de barganha e arca com custos de transporte e colheita da fruta, o que acaba se refletindo num lucro líquido menor para o produtor.

A venda do restante da produção via mercado spot para os canais alternativos também é vantajosa para o produtor em vários aspectos: (a) não há barreiras de escala; (b) os preços recebidos são maiores; (c) reduzem os riscos associados à incerteza de contratos incompletos realizados com a indústria e a incerteza em relação à variação de preço, já que nas negociações via mercado o preço é negociado no momento da venda; (d) o produtor tem a possibilidade de escoar as frutas temporãs e aquelas variedades não desejadas pelas processadoras; (e) melhoram as condições de recebimento do produtor, já que via mercado o pagamento é feito à vista, compensando o parcelamento feito pela indústria; (f) permite um melhor planejamento da colheita e do transporte, que é realizada em poucos dias depois do fechamento do negócio, enquanto na venda com contrato para a indústria o produtor deve esperar que a compradora determine a data da entrega; (g) reduzem os custos de transporte, já que nas transações via mercado estas despesas são cobertas pelo comprador e (h) dá maior flexibilidade para o produtor conquistar novos compradores, já que nem toda produção está comprometida com a indústria com contratos de médio e longo prazos. Portanto, pelo lado do produtor, a adoção de arranjos plurais é uma decisão que, diante das restrições impostas em termos de escala, permite explorar algumas vantagens que cada arranjo oferece.

\subsection{Grau de participação do produtor em organização social}

O grau de participação dos citricultores em organizações sociais é uma variável que também influencia na governança empregada pelo produtor. A tabela 2 mostra que os citricultores que empregam formas plurais se associam mais que os produtores que coordenam suas transações por meio de um único mecanismo de coordenação. 
A barreira da escala de comercialização, ou seja, a preferência pela compra de toda a produção dos citricultores maiores, contribui para explicar o efeito positivo que essa variável tem sobre a probabilidade de adoção de formas plurais. Como os produtores menores têm dificuldade de escoar toda sua produção para um único comprador, a participação em organizações como sindicatos e entidades de representação setorial aumentam suas chances de obter informações essenciais à negociação com outros canais de distribuição, de ampliar seu poder de barganha e, consequentemente, de atuar em outros arranjos que não os contratuais com a indústria. Já a maior participação do produtor em pools de comercialização aumenta a probabilidade dos pequenos atingirem a escala mínima necessária para escoarem pelo menos parte da produção para as processadoras dentro de arranjos contratuais.

De modo geral, verifica-se dificuldade de associação por parte dos produtores em relação às entidades de representação setorial como a Associtrus (Associação Brasileira de Citricultores), o que resulta na manutenção ou até aumento da assimetria de informações para o produtor negociar nos mercados e na baixa ou nenhuma influência nas decisões políticas voltadas para o setor citrícola. Quanto aos pools de comercialização, a participação dos produtores é mais intensa. Das transações de compra e venda de laranja analisadas na safra 2003/04, 53\% deram-se via pools.

\subsection{Nível de escolaridade do produtor}

A heterogeneidade de nível educacional dos produtores, bem como a assimetria de opiniões, interesses e interpretações podem representar um entrave ao desenvolvimento destes atores, principalmente quando comparado à homogeneidade de interesses e ao maior poder de aglutinação da indústria processadora.

De modo geral, o nível de escolaridade do produtor de laranja é baixo, conforme mostra a tabela 2 . Os produtores que empregam formas plurais estudam, em média, menos tempo que aqueles que empregam uma única governança, fato que pode ser explicado pela predominância de citricultores de pequeno porte no primeiro grupo, com poucas condições de estudo em função de morarem na propriedade rural e de se dedicarem quase que integralmente à atividade agrícola, destinando apenas $15 \%$ do seu tempo total a trabalhos e atividades fora da propriedade. Já no grupo de citricultores que emprega uma única governança predominam os de grande porte, cuja maioria reside na cidade e dedica cerca de $30 \%$ do seu tempo a atividades fora da propriedade, fazendo um curso superior.

O efeito negativo dessa variável nos modelos estimados significa que quanto maior o nível de escolaridade do produtor, menor a probabilidade de ele vender para múltiplos canais com governanças distintas e, consequentemente, maior a probabilidade de ele empregar uma única forma de coordenação. Isso pode ser explicado pelo fato de o maior nível de escolaridade influenciar o acesso do produtor ao conhecimento, aumentando a capacidade desse ator se adaptar às mudanças 
tecnológicas necessárias para melhorar a qualidade e a produtividade do seu pomar, facilitando a negociação de toda sua produção com um único comprador e, portanto, usando uma só governança. O maior nível de escolaridade também pode agir no sentido de ampliar a capacidade do produtor em buscar e interpretar as informações necessárias para o processo de negociação, reduzindo a assimetria informacional e facilitando a venda dedicada exclusivamente à indústria.

\subsection{Tempo de transporte até o ponto de entrega da laranja}

Maior tempo de transporte até o ponto de entrega da fruta vendida pode significar dificuldade de acesso a mercados, sobretudo àqueles que comercializam a laranja in natura. Isso porque estes compradores são os que, na maioria das vezes, arcam com os custos de transporte, inviabilizando a transação. Portanto, há uma distância e um tempo máximo de transporte entre o comprador e o pomar que torna viável a transação (especificidade locacional).

É possível verificar pela tabela 2 que o tempo médio de transporte para os produtores plurais é maior que o tempo médio para os produtores singulares, o que caracteriza uma especificidade locacional maior no segundo grupo analisado.

O efeito positivo dessa variável sobre a probabilidade de adoção de formas plurais já era esperado, ou seja, quanto mais distante o produtor está dos compradores potenciais, mais difícil fica negociar toda sua produção com um único comprador empregando determinada governança, já que a preferência vai ser por fornecedores mais próximos. Assim, a distância acaba inviabilizando a "singularidade", fazendo com que a venda para múltiplos canais com governanças plurais se torne a única opção para muitos produtores. Sobretudo no caso das vendas para os canais alternativos, em que a especificidade locacional é mais importante pelo fato desses agentes cobrirem as despesas de transporte da fruta, a proximidade e o tempo reduzido de transporte são fundamentais para a escolha do produtor. As processadoras também beneficiam os produtores mais próximos, pagando um preço maior pela sua fruta, o que explica, também, o fato do preço pago pela caixa de laranja ser menor no grupo que emprega o mix contratual.

\subsection{Preço médio recebido pelo produtor}

Analisando na tabela 2 cada estrutura de governança de forma isolada, é possível constatar que nas transações realizadas via mercado spot encontra-se o maior preço recebido pela caixa da fruta, sendo esse o incentivo para o produtor adotar essa governança. Contudo, todas as formas de coordenação empregadas de maneira isolada permitem ao produtor obter preços superiores às formas de coordenação empregadas de forma combinada, ou seja, os citricultores que decidem pelo mix contratual não conseguem se beneficiar de preços mais altos. Uma possível explicação para isso é o fato de os produtores plurais serem menores, com menor nível de escolaridade e menor capacidade de negociação. 
A constatação de que a maior probabilidade de adoção de formas plurais está relacionada ao recebimento de preços menores pelo citricultor reflete uma desvantagem do emprego do mix contratual. Esse fato enfraquece o argumento de que o emprego de várias governanças permite aproveitar o melhor de cada arranjo, já que o maior preço uma variável importante na decisão de compra - não foi aproveitado.

\subsection{Atributos das transações}

Para verificar se existe alinhamento entre os atributos das transações e a governança empregada pelo produtor, testando o primeiro argumento apresentado na revisão teórica sobre a ocorrência de formas plurais, será feita uma análise das transações de venda de laranja realizadas pelos produtores que empregam uma única forma de coordenação e por aqueles que adotam o mix contratual, caracterizando-as segundo a frequência, incerteza e especificidade de ativos. Para cada um dos atributos da transação, foi construída uma proxy, captada através das perguntas e respostas dos questionários aplicados nos produtores da região pesquisada. $\mathrm{O}$ quadro abaixo mostra a construção dessas proxies:

Quadro 1. Construção das proxies para a análise dos atributos das transações citrícolas.

\begin{tabular}{|c|c|c|}
\hline Atributo & Proxy & Interpretações \\
\hline Frequência & $\begin{array}{l}\text { Número de transações realizadas durante } \\
\text { o ano/safra. }\end{array}$ & $\begin{array}{l}\text { - Quanto maior o } \\
\text { número de transações } \\
\text { com um comprador } \\
\text { maior a frequência. }\end{array}$ \\
\hline Incerteza & $\begin{array}{l}\text { Diferença entre o preço recebido pelo } \\
\text { produtor pela caixa de laranja }(40,8 \mathrm{~kg}) \text { e o } \\
\text { preço esperado. }\end{array}$ & $\begin{array}{l}\text { - A transação é marcada } \\
\text { por incerteza quando o } \\
\text { preço recebido pelo } \\
\text { produtor é diferente do } \\
\text { preço esperado (maior } \\
\text { ou menor). }\end{array}$ \\
\hline $\begin{array}{l}\text { Especificidade } \\
\text { de ativos }\end{array}$ & $\begin{array}{l}\text { Física: se houver presença de investimentos } \\
\text { em irrigação e/ou produção em grande } \\
\text { escala da variedade de laranja Pêra Rio; } \\
\text { Humana: se houver presença de } \\
\text { investimentos em assistência técnica e em } \\
\text { cursos de capacitação; } \\
\text { Locacional: quando o tempo de transporte } \\
\text { da propriedade rural até o ponto de entrega } \\
\text { da laranja é menor que } 1 \text { hora ( } 60 \text { minutos); } \\
\text { Dedicada: se o produtor vendeu para o } \\
\text { mesmo e único comprador há pelo menos } \\
3 \text { safras consecutivas; } \\
\text { Geral: se a laranja teve que ser vendida a } \\
\text { um preço mais baixo caso não tenha sido } \\
\text { destinada a um comprador específico. }\end{array}$ & $\begin{array}{l}\text { - A transação envolve } \\
\text { ativos específicos } \\
\text { quando pelo menos } \\
\text { duas dentre as cinco } \\
\text { especificidades ao lado } \\
\text { são detectadas. }\end{array}$ \\
\hline
\end{tabular}

Fonte: Pesquisa de campo. 


\subsubsection{Frequência das transações}

A frequência com que a relação entre as partes é estabelecida é um atributo importante, porque quanto mais transações houver, maior a necessidade de salvaguardas contratuais para lidarem com imprevistos decorrentes de incompletude contratual (Williamson, 1985). Por outro lado, maior a possibilidade de diluir os custos de adoção de um mecanismo de governança complexo, como o contrato.

Nas vendas para a indústria processadora de suco coordenadas por contrato, considerando que cada lote vendido tem que ter uma escala mínima, o produtor pode realizar uma, duas, três negociações no ano ou até menos, quando o contrato tem a duração de duas ou três safras. No caso da venda para os canais alternativos governadas por mercado spot, as negociações também são pouco frequentes durante a safra.

A tabela 4 mostra que no grupo que emprega uma única forma de coordenação as transações são mais recorrentes que no grupo que adota formas plurais. É possível verificar, também, a existência de alinhamento entre esse atributo e a forma de coordenação empregada pelo citricultor, ou seja, o número de transações é superior nas governanças que promovem um maior controle, como é caso do contrato, da hierarquia e da quase integração.

Portanto, uma possível explicação para o emprego de formas simultâneas de coordenação é o fato de as transações diferirem no atributo "frequência".

Tabela 4. Frequência das transações citrícolas - safra 2003/04.

\begin{tabular}{lcccccc}
\hline Governança & Frequência & Média & Mínimo & Máximo & D.P & Valor P \\
\hline Forma Singular & $\mathbf{1 5 1}$ & $\mathbf{2 , 8 8}$ & $\mathbf{1}$ & $\mathbf{6}$ & $\mathbf{1 , 1 7 1 5}$ & 0,0000 \\
Hierarquia & 3 & 3,00 & 3 & 3 & 0,0000 & \\
Contrato & 122 & 3,03 & 1 & 6 & 1,1637 & \\
Mercado & 26 & 2,15 & 1 & 4 & 1,0077 & \\
Formas Plurais & $\mathbf{8 8}$ & $\mathbf{1 , 6 9}$ & $\mathbf{1}$ & $\mathbf{3}$ & $\mathbf{0 , 7 3 2 8}$ & \\
Hierarquia & 2 & 2,00 & 2 & 2 & 0,0000 & \\
Quase integração & 3 & 3,00 & 3 & 3 & 0,0000 & \\
Contrato & 45 & 1,91 & 1 & 3 & 0,7250 & \\
Mercado & 38 & 1,28 & 1 & 3 & 0,5107 & \\
\hline
\end{tabular}

Fonte: Pesquisa de campo.

\subsubsection{Incerteza}

A incerteza, segundo Williamson (1985), constitui-se em qualquer tipo de perturbação endógena que afeta o processo de troca, podendo ser primária (deriva de atitudes aleatórias e mudanças imprevisíveis) ou secundária (deriva do fato daquele que toma decisões não poder conhecer os planos e intenções da outra parte). 
As principais incertezas relacionadas à produção e comercialização de laranja são: volume, qualidade e preços, sendo que somente o último tipo pode ser minimizado através da escolha de uma estrutura de governança eficiente. As variáveis que explicam a incerteza em relação ao volume são aleatórias, já que é praticamente impossível garantir que a doença ou a praga será controlada, mesmo seguindo as normas técnicas existentes. Qualquer variação de um componente não controlado no campo pode alterar o resultado da operação, como pode ocorrer com a mudança de clima.

Quanto à qualidade da laranja, a incerteza vem da especificidade temporal, já que a fruta pode perder a qualidade ao longo do tempo. Essa variável pode ser tratada pelo oportunismo, quando estiver relacionada à assimetria de informação entre as partes, caracterizando uma incerteza secundária. Esse tipo de incerteza afeta mais a capacidade de negociar dos agentes que participam dos canais alternativos, já que a qualidade da laranja é o diferencial para obter preços melhores. No caso da indústria, embora essa incerteza também seja elevada, é mais comum a mensuração dos atributos responsáveis pela qualidade da laranja destinada à produção de suco através da análise física ou química da fruta.

Outra incerteza nas transações entre produtor de laranja e canais de comercialização vem da variação de preços da fruta comercializada. Essa incerteza pode ser considerada do tipo primária se estiver relacionada às oscilações da oferta de laranja em função de fatores aleatórios (clima, pragas, etc.) e do tipo secundária se estiver associada à manipulação ou domínio de informações por uma parte da transação, podendo, nesse caso, ser minimizada por meio da escolha de uma estrutura de governança eficiente.

Considerando a variação entre o preço recebido e o preço esperado pelo citricultor como proxy para a mensuração da incerteza, através de uma dummy representada por (0) quando o preço recebido for igual ao esperado e (1) quando o preço recebido for diferente do esperado, espera-se que a presença de incerteza esteja diretamente relacionada à maior probabilidade de adoção de formas de coordenação com maior grau de controle.

A tabela 5 mostra que essa variável afeta de forma estatisticamente igual os dois grupos de produtores analisados. Contudo, o mais importante é a constatação de alinhamento entre esse atributo "incerteza" e a forma de governança empregada pelo citricultor, cuja incerteza existe em maior proporção nas governanças que exercem maior controle sobre as condições da transação, justificando a adoção de contrato nas vendas para a indústria e de hierarquia e quase integração por parte de alguns produtores. Por outro lado, a menor incidência de incerteza nas transações com os membros dos canais alternativos reduz o risco de comportamento oportunista e favorece as negociações via mercado spot. 
Tabela 5. Diferença entre preço recebido e preço esperado ( $R$ /caixa de laranja) - safra 2003/04.

\begin{tabular}{lcccccc}
\hline Governança & $\begin{array}{c}\text { Frequência } \\
\text { (Preço recebido } \\
\text { diferente do } \\
\text { esperado) }\end{array}$ & $\begin{array}{c}\text { \% } \\
\text { Forma Singular }\end{array}$ & $\begin{array}{c}\text { Frequência } \\
\text { (Preço recebido } \\
\text { igual ao } \\
\text { esperado) }\end{array}$ & $\%$ & $\begin{array}{c}\text { Frequência } \\
\text { TOTAL }\end{array}$ & Valor P \\
Hierarquia & $\mathbf{9 0}$ & $\mathbf{5 9 , 6}$ & $\mathbf{6 1}$ & $\mathbf{4 0 , 4}$ & $\mathbf{1 5 1}$ & 0,7307 \\
Contrato & 3 & 100,0 & 0 & 0,0 & 3 & \\
Mercado & 75 & 61,5 & 47 & 38,5 & 122 & \\
Formas Plurais & $\mathbf{4 9}$ & 46,2 & 14 & 53,8 & 26 & \\
Hierarquia & 2 & $\mathbf{5 5 , 7}$ & $\mathbf{3 9}$ & $\mathbf{4 4 , 3}$ & $\mathbf{8 8}$ & \\
Quase integração & 3 & 100,0 & 0 & 0,0 & 2 & \\
Contrato & 28 & 100,0 & 0 & 0,0 & 3 & \\
Mercado & 16 & 42,2 & 17 & 37,8 & 45 & \\
\hline
\end{tabular}

Fonte: Pesquisa de campo.

A maior incerteza nos arranjos contratuais com a indústria pode ser explicada pelo fato de a safra ser negociada antecipadamente, de modo que a cotação do produto pode evoluir diferentemente do esperado. Assim, uma das partes fica mais propensa a romper o acordo, colocando a necessidade de contratos antecipados com preços variáveis. Já nas vendas para os canais alternativos, a negociação do preço se dá no momento da venda, o que reduz a probabilidade de haver uma variação entre o valor recebido e o esperado pelo produtor.

Além disso, é importante considerar a assimetria de estrutura de mercado, de recursos e de informação existente entre a indústria e os produtores de laranja, o que acaba gerando maior incerteza nas negociações com esse canal de distribuição ${ }^{3}$. Esse argumento comprova a ideia de Argyres e Liebeskind (1999) de que diferenças no poder de barganha exercem impactos importantes na escolha da governança, deixando disponíveis apenas um conjunto limitado de mecanismos. No caso analisado, há diferenças no poder de barganha entre o produtor e os membros dos canais de distribuição, que acabam definindo qual será o mecanismo que coordenará as transações.

${ }^{3}$ Além do domínio da informação, outras estratégias são empregadas pela indústria para reduzir o preço de referência a ser pago pela caixa de laranja, aumentando a incerteza do citricultor nas negociações com esse canal: a) a manutenção de pomares próprios, aumentando seu poder de barganha no início de cada safra; b) o compartilhamento e não divulgação de informações sobre estoques estratégicos de suco de acordo com interesses de fechamento de preços de contratos futuros; $c$ ) acordo entre indústrias para não divulgação de seus custos de produção e distribuição de suco, bem como da produtividade média para transformação de caixas de laranja em toneladas de suco processado; d) administração de preços internos e externos através do controle da oferta no Brasil e na Flórida; e) pagamento de preços diferenciados a produtores, segundo critérios não definidos; f) não divulgação com antecedência pelas indústrias da logística desejada para a colheita da fruta, o que dificulta a organização da atividade e a formação dos consórcios de produtores (PAULILLO, et al, 2006). 


\subsubsection{Especificidade de ativos}

A qualidade da laranja comercializada nos diversos canais de distribuição está ligada às características físicas, temporais e de localização dos pomares, as quais, em muitas situações, podem tornar-se entraves para a produção e negociação dos citricultores, influenciando na escolha da forma de coordenação.

Há um tempo prolongado para os pomares entrarem na fase produtiva e um período específico do ano no qual a maturação da laranja está no ponto ótimo para a colheita, sendo que o produtor não pode controlar totalmente o ciclo biológico do seu produto. A diversidade de variedades e a possibilidade de ocorrerem colheitas temporãs dificultam um planejamento preciso da colheita. Por outro lado, como se trata de um produto perecível que perde qualidade com o tempo de espera para esmagamento, existe um elevado custo de se transferir a laranja de um período para outro, o que explica a especificidade temporal desse produto.

A especificidade física pode vir dos seguintes aspectos: (a) dos atributos exigidos pela indústria de suco, como teores de açúcar diferentes e ratio ${ }^{4}$ considerado ideal as características mais importantes que influenciam a qualidade do suco de laranja são os açúcares, ácidos, o gosto ou sabor, a concentração e a vitamina C, que são avaliados por diferentes métodos para defini-lo e classificá-lo; (b) da variedade de laranja produzida - o citricultor que produz uma maior quantidade de laranja Pêra Rio tem mais facilidade de vender toda sua produção para a indústria, pois essa é a variedade preferida pelas processadoras, que chegam a pagar um preço superior pela caixa; (c) a especificidade física mais relevante dentre os produtores analisados vem dos investimentos na produção agrícola, principalmente os destinados à irrigação. Esses investimentos estão presentes tanto na produção da fruta que será comercializada exclusivamente nos canais alternativos via mercado, em que o produtor zela pela elevada qualidade da fruta para mesa visando conseguir um preço maior, quanto na produção da laranja que será destinada exclusivamente à indústria de suco, já que o produtor consegue uma maior produtividade do pomare, consequentemente, maior escala. Para avaliar a presença de especificidade física nas transações realizadas, foram consideradas como proxies a existência de investimentos em irrigação e o fato de a maior parte da produção de laranja ser da variedade Pêra Rio.

A produção de citros também envolve especificidade humana, principalmente no que diz respeito ao conhecimento e habilidades especiais na produção e na colheita da fruta destinada ao consumo in natura (sobretudo a laranja vendida para os barracões). Para avaliar a presença desse tipo de especificidade, a variável escolhida foi a existência de investimentos em assistência técnica e em cursos de capacitação por parte do citricultor.

Já a especificidade locacional se dá quando a maturação da fruta ocorre em locais distantes dos pontos de entrega, dificultando a logística e aumentando os

\footnotetext{
${ }^{4}$ Ratio é a relação entre o brix (\% de sólidos solúveis no suco) e a acidez.
} 
custos de distribuição. Esse tipo de especificidade, avaliada pela proxy "tempo de transporte", é mais relevante no grupo de produtores que emprega uma única governança, em que a proximidade é uma variável importante na escolha do comprador para reduzir custos de distribuição.

A especificidade dedicada é criada pela dependência que o produtor de laranja apresenta em relação a um comprador, ou seja, surge à medida que ele faz investimentos para ofertar laranja a um cliente específico. Esse tipo de especificidade é mais evidente no grupo de produtores que vende laranja exclusivamente para um canal - empregando uma forma de coordenação - do que naquele que vende para diversos canais - empregando o mix contratual -, tendo em vista que os citricultores do primeiro grupo comercializam com apenas uma empresa compradora durante todo o ano/safra ${ }^{5}$, constituindo-se em fornecedores cativos.

O fato é que esse conjunto de especificidades cria uma relação de dependência entre as partes da transação, tornando os agentes presos à mesma. Isso porque, se a relação termina, o valor do investimento realizado diminui em outro uso e o comprador fica comprometido, já que não pode recorrer a fontes alternativas de oferta e obter condições favoráveis em outra transação. Considerando esse fato, procurou-se capturar o efeito de todas as especificidades em conjunto por meio da verificação da perda de valor quando a laranja é destinada a um uso alternativo. Assim, foi questionado se o produtor consegue vender sua fruta, cuja produção exigiu investimentos específicos, a outros compradores, sem perda de preço.

Para a construção da tabela 6, que identifica a presença de ativos específicos nas transações realizadas pelos dois grupos de produtores, o seguinte critério foi empregado:

- SIM, a especificidade de ativos está presente: quando a transação é marcada por, pelo menos, dois tipos de especificidades dentre os cinco tipos analisados;

- NÃO, a especificidade de ativos não está presente: quando a transação apresenta apenas um ou nenhum tipo de especificidade dentre os cinco analisados.

A tabela 6 mostra que a especificidade está mais presente nas negociações dos produtores que empregam uma única governança. Tal fato, como já comentado anteriormente, deve-se principalmente à existência de especificidades físicas, locacionais e dedicadas a um comprador específico. A maioria dos produtores que participam desse grupo alegou ter uma redução de preço caso necessitem vender sua produção para outros compradores, configurando a perda de valor gerada pela especificidade dos investimentos realizados. Já no grupo de produtores que emprega formas plurais, os investimentos em ativos específicos aparecem em menor proporção. A especificidade está presente, sobretudo, nas transações de venda para a indústria (contratos), quando o produtor, em grupo, adota o tool processing e quando integra a comercialização da fruta através de barracões.

\footnotetext{
${ }^{5}$ A presença de especificidade dedicada foi considerada quando o citricultor vendeu para o mesmo comprador e exclusivamente para ele há pelo menos três safras consecutivas.
} 
Tabela 6. Presença de especificidade dos ativos nas transações citrícolas - safra 2003/04.

\begin{tabular}{lcccccc}
\hline Governança & $\begin{array}{c}\text { Frequência } \\
\text { (SIM) }\end{array}$ & $\%$ & $\begin{array}{c}\text { Frequência } \\
\text { (NÂO) }\end{array}$ & $\%$ & $\begin{array}{c}\text { Frequência } \\
\text { TOTAL }\end{array}$ & Valor P \\
\hline Forma Singular & $\mathbf{1 1 3}$ & $\mathbf{7 4 , 8}$ & $\mathbf{3 8}$ & $\mathbf{2 5 , 2}$ & $\mathbf{1 5 1}$ & 0,0465 \\
Hierarquia & 3 & 100,0 & 0 & 0,0 & 3 & \\
Contrato & 102 & 83,6 & 20 & 16,4 & 122 & \\
Mercado & 8 & 30,7 & 18 & 69,3 & 26 & \\
Formas Plurais & $\mathbf{4 6}$ & $\mathbf{5 2 , 3}$ & $\mathbf{4 2}$ & $\mathbf{4 7 , 7}$ & $\mathbf{8 8}$ & \\
Hierarquia & 2 & 100,0 & 0 & 0,0 & 2 & \\
Quase integração & 3 & 100,0 & 0 & 0,0 & 3 & \\
Contrato & 32 & 71,1 & 13 & 28,9 & 45 & \\
Mercado & 9 & 23,7 & 29 & 76,3 & 38 & \\
\hline
\end{tabular}

Fonte: Pesquisa de campo.

De modo geral, as especificidades de ativos envolvidas desde a plantação da fruta até sua recepção no comprador e a elevada incerteza presente nesse tipo de atividade implicam na necessidade de contratos bem desenhados para a comercialização, para que problemas derivados do oportunismo e da racionalidade limitada dos agentes não ocorram. Na maioria das transações de venda para a indústria (90\% delas), cuja presença de investimentos específicos, incerteza de preços e forte assimetria de informações contribuem para a existência de comportamento oportunista, a governança contratual é adotada, permitindo verificar o alinhamento entre os atributos das transações e a governança efetivamente empregada pela maioria dos produtores.

Já nas transações para os canais alternativos, a maioria das negociações não envolve investimentos específicos (74\% delas), sendo coordenadas sem a elaboração de contratos. Nesse caso, se o produtor não conseguir vender sua laranja para certo comprador, ele tem outras opções de compradores no mercado, sem incorrer em perda de valor. Em algumas negociações com barracões em que há investimentos físicos, humanos e locacionais específicos, a ausência de contrato por ser explicada pela confiança estabelecida entre esse agente e o comprador ao longo de vários anos de relacionamento, sendo esse o fator que reduz a incerteza e leva a um enforcement automático das condições da transação, garantindo alguma coordenação em função do interesse das partes em manter o relacionamento.

Portanto, uma possível explicação para o emprego de formas simultâneas de coordenação é o fato das transações diferirem no atributo "especificidade de ativos". 


\subsubsection{Resultados e Interpretações}

A análise feita nos itens anteriores já deu indícios de que as governanças empregadas pelos citricultores da região pesquisada estão alinhadas aos atributos das transações propostos por Williamson (1985). A elaboração de regressões usando como variáveis dependentes a "porcentagem de caixas de laranja vendidas com contrato e via mercado pelo citricultor" e como variáveis explicativas as proxies para os atributos de frequência, incerteza e especificidade de ativos permite confirmar tal alinhamento.

Para a elaboração das regressões, foram utilizados os modelos Logit e Probit, que são os mais indicados para os casos em que a variável dependente é limitada, como ocorre com a porcentagem de caixas de laranja vendidas com contrato e via mercado spot, que varia entre 0 e $100 \%$. A tabela 7 apresenta os resultados para os dois grupos de produtores.

Tabela 7. Estimações dos determinantes das formas de governança empregadas nas transações citrícolas.

\begin{tabular}{|c|c|c|c|c|c|c|c|c|}
\hline \multirow{3}{*}{$\begin{array}{l}\text { Nome da } \\
\text { variável }\end{array}$} & \multicolumn{4}{|c|}{ Participação de Contrato } & \multicolumn{4}{|c|}{ Participação de Mercado Spot } \\
\hline & \multicolumn{2}{|c|}{ LOGIT } & \multicolumn{2}{|c|}{ PROBIT } & \multicolumn{2}{|c|}{ LOGIT } & \multicolumn{2}{|c|}{ PROBIT } \\
\hline & Coeficiente & Signif. & Coeficiente & Signif. & Coeficiente & Signif. & Coeficiente & Signif. \\
\hline \multicolumn{9}{|c|}{ Forma Singular } \\
\hline Intercepto & $-1,158557$ & 0,053 & $-0,657743$ & 0,051 & 1,060463 & 0,113 & 0,560226 & 0,112 \\
\hline $\begin{array}{l}\text { Especificidade } \\
\text { de ativos }\end{array}$ & 1,587681 & 0,001 & 0,925701 & 0,002 & $-1,994111$ & 0,000 & $-1,146055$ & 0,000 \\
\hline $\begin{array}{l}\text { Frequência das } \\
\text { transações }\end{array}$ & 0,462247 & 0,096 & 0,255949 & 0,052 & $-0,411304$ & 0,095 & $-0,210417$ & 0,091 \\
\hline $\begin{array}{l}\text { Diferença de } \\
\text { preços } \\
\text { (Incerteza) } \\
\end{array}$ & 0,548031 & 0,287 & 0,355369 & 0,173 & $-0,573869$ & 0,323 & $-0,355898$ & 0,204 \\
\hline \multicolumn{9}{|l|}{ Formas Plurais } \\
\hline Intercepto & $-2,608882$ & 0,001 & $-1,603615$ & 0,000 & 2,993208 & 0,000 & 1,819043 & 0,000 \\
\hline $\begin{array}{l}\text { Especificidade } \\
\text { de ativos }\end{array}$ & 0,856740 & 0,065 & 0,541260 & 0,056 & $-1,336576$ & 0,007 & $-0,822383$ & 0,005 \\
\hline $\begin{array}{l}\text { tblFrequência } \\
\text { das transações }\end{array}$ & 0,995486 & 0,008 & 0,603663 & 0,005 & $-1,438555$ & 0,000 & $-0,865926$ & 0,000 \\
\hline $\begin{array}{l}\text { Diferença de } \\
\text { preços } \\
\text { (Incerteza) }\end{array}$ & 0,894342 & 0,068 & 0,557363 & 0,055 & $-0,589518$ & 0,263 & $-0,359302$ & 0,242 \\
\hline
\end{tabular}

Fonte: Pesquisa de campo.

Pela tabela 7, é possível verificar certa consistência entre os dois modelos estimados, nos quais as mesmas variáveis são significantes e os sinais dos coeficientes são iguais. 
Analisando os dois grupos de produtores, verifica-se que tanto a especificidade de ativos quanto a frequência das transações são variáveis significantes e têm o efeito esperado sobre a participação de contrato e de mercado na quantidade de laranja comercializada pelo produtor. Ou seja, a presença de especificidade de ativos e a maior frequência das transações aumentam a probabilidade de adoção da governança contratual e reduzem a participação da governança de mercado na quantidade de laranja comercializada, o que pode ser concluído pelo alinhamento entre esses atributos e as governanças empregadas.

Já a proxy relacionada à incerteza nas transações (diferença de preço) é significante somente para explicar a participação de contrato no grupo de produtores que emprega o mix contratual, o que pode ser justificado pelo fato de essa variável ter um comportamento estatisticamente igual nos dois grupos analisados e pela questão da incerteza não ser relevante nas transações governadas via mercado. Contudo, o sinal do seu coeficiente indica o efeito esperado sobre os mecanismos de governança adotados, ou seja, na presença de incerteza em relação ao preço recebido pelo produtor, maior a probabilidade de adoção de contrato e menor de mercado, o que também pode ser concluído pelo alinhamento.

De acordo com Williamson (1985), quanto maiores a especificidade de ativos e a incerteza e mais recorrentes as transações, maior a necessidade de controle sobre as condições da transação, o que exige respostas coordenadas das partes e compromissos mais longos para recuperar os investimentos cujo uso alternativo pode ser limitado, justificando o emprego de contratos de médio e longo prazos nas vendas para a indústria. Por outro lado, o mercado é a escolha dos citricultores nos casos em que as negociações são menos frequentes, com baixa incerteza de preços e baixa ou nenhuma especificidade de ativos ${ }^{6}$.

Portanto, a verificação de que as formas de governança empregadas para coordenar as transações entre os citricultores e os diversos canais de distribuição estão alinhadas aos principais atributos propostos por Williamson (1985) indica que esses atributos são elementos-chave para concluir dois aspectos:

(a) Que não há inabilidade por parte dos citricultores e membros dos canais de distribuição da laranja para mensurar as dimensões das transações e para identificar a solução mais eficiente em termos de governança, o que resultaria no emprego de diferentes mecanismos para governar transações similares. Assim, a coexistência de governanças distintas para coordenar transações de um mesmo produtor não é uma situação

\footnotetext{
${ }^{6}$ Em função de apenas cinco transações serem coordenadas de forma hierárquica e três por quase integração, não foi possível estimar os modelos Logit e Probit para esses casos (tamanho reduzido da amostra). Porém, os dados de estatística descritiva para as oito transações mostram a existência de ativos específicos, incerteza quanto à variação de preços e elevada frequência nas transações, o que pode ser concluído pelo alinhamento.
} 
transitória em busca do arranjo mais eficiente, mas uma situação estável em que esses arranjos plurais persistem ao longo do tempo;

(b) Que o emprego de formas plurais pelos citricultores pode ser explicado pelo fato de as transações serem diferentes em pelo menos um dos atributos. Assim, o arranjo contratual é escolhido uma vez que garante o retorno de investimentos físicos, humanos, locacionais e dedicados realizados pelo produtor e pela indústria durante a produção e a comercialização, num ambiente de elevada incerteza. Já a governança de mercado é empregada porque como a maioria das transações não exige investimentos em ativos específicos, a baixa incerteza e frequência das negociações não justificariam a adoção de mecanismos complexos e custosos como o contrato.

\section{Conclusões}

A pesquisa realizada deixou claro que a indústria é o canal de distribuição preferido pelo citricultor. Quando é possível, ele prefere destinar toda sua produção para esse comprador, com as garantias de venda e de recebimento proporcionadas pela elaboração de contratos. Outra opção para o citricultor, utilizada em menor proporção na região analisada, é vender toda a produção via mercado spot para os membros dos canais alternativos, sobretudo para os barracões (que compram quantidades maiores de laranja). As principais vantagens ao produtor desta segunda alternativa são os preços maiores, o recebimento à vista, a cobertura das despesas de colheita e transporte pelo comprador, a possibilidade de vender as frutas temporãs e as variedades não desejadas para o processamento e a redução de riscos associados à possível incompletude dos contratos realizados com a indústria.

Embora predominem as vendas de laranja exclusivas para as processadoras de suco, muitos produtores não têm essa opção disponível, ou seja, conseguem escoar apenas parte da produção para esse canal com contratos e o restante para os canais que compram quantidades menores da fruta via mercado, como é o caso dos varejistas, intermediários e representantes do mercado institucional. Portanto, há restrições ou barreiras que acabam limitando a escolha da governança empregada pelo produtor.

Uma dessas restrições é o fato de as processadoras terem interesse na dedicação dos citricultores maiores. Ou seja, a indústria tem como estratégia adquirir toda a produção dos fornecedores maiores e somente parte da produção dos fornecedores menores, completando o mix necessário para o processamento. Essa preferência vem da necessidade que as processadoras têm de garantir regularidade no seu suprimento e consistência na qualidade da matéria-prima, de aproveitar economias de escala e obter certa padronização nos preços. 
Outra restrição que também dificulta a venda de toda a produção do citricultor para a indústria, mas afeta mais intensamente a exclusividade para os barracões, vem da especificidade locacional existente na atividade citrícola. $\mathrm{O}$ fato de muitos produtores estarem distante dos compradores acaba inviabilizando muitas transações com um único comprador. Nesse caso, a opção para esses citricultores acaba sendo distribuir sua produção entre os que estão mais próximos, resultando na pluralidade de formas de coordenação.

Portanto, uma das conclusões acerca dos determinantes das formas plurais no caso citrícola está relacionada ao fato de existirem necessidades específicas por parte dos compradores que pertencem a canais de distribuição distintos (quantidade, qualidade, localização etc.), e essas necessidades geram restrições que podem explicar a decisão por múltiplos canais e governanças para coordenar as transações do mesmo citricultor.

Diante da menor possibilidade que os pequenos e médios citricultores têm de atuar exclusivamente no arranjo contratual da indústria, a participação em associações de interesse e em pools de comercialização aumentam as chances de o produtor conseguir negociar nesse arranjo e em outros também. Considerando que esses produtores apresentam um nível mais baixo de escolaridade, o que dificulta o acesso e a interpretação de informações essenciais ao processo de negociação com os compradores da laranja, a participação nessas organizações torna-se ainda mais relevante.

Embora o produtor que possui contratos com a indústria e emprega o mercado spot para coordenar suas transações com os canais alternativos tire proveito de algumas vantagens proporcionadas por cada governança (Mercado: reduz a incerteza quanto à variação dos preços, melhora suas condições de recebimento, isenta das despesas de colheita e transporte, vende as variedades temporãs e as não desejadas para processamento. Contrato: maior garantia de venda e de recebimento), não é possível concluir que o emprego de formas plurais seja uma estratégia que permite ao citricultor aproveitar o melhor de cada forma, produzindo resultados maiores que os obtidos com o emprego de uma única forma. Isso porque foi verificado que os citricultores plurais recebem preços mais baixos pela laranja vendida e apresentam lucro líquido menor que os produtores "singulares".

Outra conclusão é a de que o produtor emprega governanças distintas para coordenar suas transações com os canais de distribuição porque essas transações são diferentes em pelo menos um dos atributos: especificidade de ativos, frequência ou incerteza.

Do lado do citricultor, as transações de venda de laranja para a indústria processadora são relativamente frequentes e ocorrem num ambiente marcado pela incerteza ligada à assimetria de informações, à variação de preços e pela presença de especificidades físicas, humanas, locacionais e dedicadas, condições em que a teoria indica o emprego de governanças que promovam um nível maior 
de controle, como o contrato, a quase integração e a integração; efetivamente empregados na prática. Pela ótica da indústria, a necessidade de garantir regularidade no volume processado, minimizando a capacidade ociosa da planta e aproveitando as economias de escala, e de obter consistência na qualidade da fruta processada tornam a governança contratual a mais eficiente para coordenar as transações de compra de laranja, reduzindo os riscos de ações oportunistas por parte dos fornecedores.

Já nas negociações com os canais alternativos, a frequência e incerteza reduzidas e a baixa ou nenhuma presença de investimentos específicos na produção e na comercialização da fruta tornam a governança de mercado a mais indicada pela Economia dos Custos de Transação (ECT), sendo, de fato, a mais empregada pelo produtor. No caso das transações com os compradores que adquirem a laranja com mais frequência ou quando há algum investimento específico relevante, o elevado grau de confiança e o interesse na continuidade da relação são os mecanismos de enforcement que substituem o contrato.

Por meio da análise das estatísticas descritivas e dos coeficientes das proxies estimadas para os principais atributos das transações, foi possível verificar a existência de alinhamento entre esses atributos e as governanças empregadas pelo citricultor, fazendo destes fatores-chave para explicar a ocorrência de formas plurais. Esse fato permite concluir que os atores citrícolas não apresentam inabilidades para mensurar esses atributos e, sobretudo, para identificar a solução mais eficiente em termos de governança, tornando o mix contratual uma situação estável e não transitória. Outro argumento que contribui para a comprovação de que o mix contratual representa uma situação definitiva é a verificação de que $96 \%$ dos produtores que empregavam formas plurais na safra 2003/04 o continuaram fazendo durante as quatro safras seguintes, com a adoção das mesmas estruturas de governança.

\section{Referências Bibiográficas}

ARGYRES, N.S., LIEBESKIND, J. Contractual commitments, bargaining power, and governance inseparability. Academy of Mangement Review, v. 24, n.5, p.49-63, jan. 1999.

AZEVEDO, P.F.; SILVA, V.L.S.S. Contractual mix analysis in the brazilian franchising. In: INTENATIONAL SOCIETY FOR NEW INSTITUTIONAL ECONOMICS, set. 2001, Berkely. Disponível em: $<$ http://www.isnie.org/ISNIE01>. Acesso em: 20 julho 2007.

BAI, C.; TAO, Z. Contract mix and ownership. Working paper. 41p, 1996.

BRADACH, J.L. Using the plural form in the management of restaurant chains. Administrative Science Quarterly, v.42, n.2, p. 276-303, jun. 1997. 
BRADACH, J.L. e ECCLES, R.G. Price, autority and trust: from ideal types to plural forms. Annual Review of Sociology, v.15, p.97-118, 1989.

BROUSSEAU, E. e CODRON, J.M. The Hybridization of governance structures: supplying french supermarkets with off-season fruit. Montpellier, France, 1997. Mimeo.

CAVE, R.E., MURPHY, W.F. Franchising: firms, markets and intangible assets. Economic Journal, v.42, n.4, p.572-586, apr., 1976.

EHRMANN, T., SPRANGER, G. Successful franchising using the plural form. In: WINDSPERGER, J. et al. Economics and management of franchising networks. Heidelberg: Physica-Verlag, 2004. p. 89-109.

FAN, P.H.J. Price uncertainty and vertical integration: evidence from the U.S. petrochemical industry. Pittsburgh: Center for Research on Contracts and the Structure of Interprise, 1995. $31 \mathrm{p}$.

GALLINI, N.; LUTZ, N. Dual distribution and royalty fees in franchising. Journal of Law, Economics \& Organization, v.8, n.3, p.471-501, oct., 1992.

GIL, A.C. Métodos e técnicas de pesquisa social. 2.ed. São Paulo: Atlas, 1987. 206p.

LEWIN-SOLOMONS, S.B. Innovation and authority in franchise systems: an empirical exploration of the plural form. Journal paper, n. j-18005 of the Iowa Agriculture and Home Economics Experiment Station, Amos Iowa, 1999.

MINKLER, A, PARK, T.A. Asset specificity and vertical integration in franchising. Review of Industrial Organization, v.9, n. 7, p.409-423, aug., 1994.

NORTH, D.C. Institutions, institutional change and economic performance Cambridge: Cambridge University Press, 1990. 152 p.

PAULILlO, L.F.(org). Agricultura e citricultura no Brasil: diferenças e dominâncias. Rio de Janeiro: E-paper, 2006. 442 p.

RUBIN, P.H. The Theory of the firm and the structure of franchise contract. Journal of Law and Economics, v.21, n.1, p.223-233, apr., 1978.

SIMON, H.A. Rationality as process and as product of thought. The American Economic Review, v.68, n.2, p.1-16, may, 1978.

WILLIAMSON, O. E. Calculativeness, trust and economic organization. Journal of Law and Economics, v.36, n.1, part 2, p.453-486, Apr., 1993.

Comparative economic organization: the analysis of discrete structural alternatives. Administrative Science Quartely, v.36, n.2, p. 269-296, Jun.,1991. 
. The economic institutions of capitalism: firms, markets, relational contracting. New York: The Free Press, 1985. 450 p.

WOOLDRIDGE, J.M. Introdução à Econometria: uma abordagem moderna. São Paulo: Thomson Pioneira, 2006. 684p.

ZYLBERSZTAJN, D.; NOGUEIRA, A.C.L. Estabilidade e difusão de arranjos verticais de produção: uma contribuição teórica. Economia e Sociedade, v.11, n.2, p.329-346, jun./dez., 2002. 